Revista 2020

\title{
Estrategias para desarrollar la convivencia y la paz desde la educación*
}

\author{
Marleny Carreñoa - Hugo Rozo Garcíab
}

\begin{abstract}
Resumen: El presente artículo es resultado de la revisión sistemática de literatura que tenía como propósito identificar las diferentes estrategias que han abordado la convivencia y paz desde la educación entre el 2013 y 2017. El proceso de revisión se estructuró en tres momentos los cuales permitieron consolidar la revisión planteada y abordar el fenómeno estudiado. Los resultados evidencian que es un tema amplio con diferentes matices, se puede observar que existen esfuerzos por fomentar la convivencia y paz a través de prácticas de aula e institucionales que intentan seguir lineamientos políticos y académicos, pues está claro que son muchos los beneficios de reconocer, identificar y brindar herramientas para solucionar los conflictos dentro y fuera de las instituciones educativas. El principal resultado fue la agrupación de esas iniciativas en cuatro grandes estrategias, que permiten ver con mayor claridad los esfuerzos que se están desarrollando y los diferentes estadios que ha tenido el objeto de estudio.
\end{abstract}

Palabras clave: competencias ciudadanas; convivencia y paz; entorno escolar; revisión a la literatura.

Recibido: 15 de enero de 2020. Aceptado: 24 de marzo de 2020

Disponible en línea: 22 de octubre de 2020.

Cómo citar: Carreño, M. y Rozo García, H. A. (2020). Estrategias para desarrollar la convivencia y paz desde la educación. Academia y Virtualidad, 13(2), 35-56. https://doi.org/10.18359/ravi.4501

* Artículo de revisión

a Magíster en informática educativa. Profesora del Colegio Antonio Nariño, Bogotá, Colombia. Correo electrónico: marlenycaba@unisabana.edu.co. ORCID: http://orcid.org/0000-0001-9918-2454

b Magíster en informática educativa. Profesor e investigador del Centro de Tecnologías para la Academia de la Universidad de La Sabana, Chía, Colombia. Correo electrónico: hugoroga@unisabana.edu.co ORCID: http://orcid.org/0000-0001-9745-7987 


\section{Strategies to develop coexistence and peace from education}

Abstract: This article is the result of a systematic literature review to the different strategies that have addressed coexistence and peace from education between 2013 and 2017. The review process was structured in three moments, which allowed consolidating the proposed review and addressing the phenomenon studied. The results show that it is a broad subject with different nuances. It can be observed that there are efforts to promote coexistence and peace through classroom and institutional practices that try to follow political and academic guidelines since it is clear that there are many benefits in recognizing, identifying, and providing tools to solve conflicts inside and outside educational institutions. The main result was finding out that these initiatives can be grouped into four major strategies, which allow us to see more clearly the efforts being developed and the different stages that the object of study has had.

Keywords: citizen competences; coexistence and peace; school environment; literature review

\section{Estratégias para desenvolver a convivência e a paz a partir da educação}

Resumo: O presente artigo é resultado da revisão sistemática de literatura que tinha como propósito identificar as diferentes estratégias que abordaram a convivência e a paz a partir da educação entre 2013 e 2017. O processo de revisão estruturou-se em três momentos, os quais permitiram consolidar a revisão proposta e abordar o fenômeno estudado. Os resultados evidenciam que é um tema amplo com diferentes matizes, também pode ser observado que existem esforços por fomentar a convivência e a paz por meio de práticas de sala de aula e institucionais que tentam seguir diretrizes políticas e acadêmicas, pois está claro que são muitos os benefícios de reconhecer, identificar e oferecer ferramentas para solucionar os conflitos dentro e fora das instituições educativas. O principal resultado foi o agrupamento dessas iniciativas em quatro grandes estratégias, que permitem ver com maior clareza os esforços que se estão desenvolvendo e as diferentes fases que o objeto de estudo tem tido.

Palavras-chave: competências cidadãs; convivência e paz; meio escolar; revisão da literatura 


\section{Introducción}

En los últimos catorce años, Colombia y otros países de Iberoamérica se han caracterizado por ser países que han trabajado en la construcción constante de la paz, logrando poco a poco que se reconozcan sus esfuerzos y su incansable búsqueda de caminos de reconciliación a nivel internacional. De esta manera, se ha hecho necesario que cada individuo se involucre desde sus acciones diarias y la práctica de valores en comunidad, además de contribuir en la transformación de los entornos donde se desenvuelven los niños, niñas y los jóvenes. Para el caso de Colombia, es preciso mencionar que se habla de competencias ciudadanas a partir del año 1998, postulando que los ciudadanos logren fortalecer sus valores a través de la interacción en la escuela, logrando que no solo se evalúen competencias académicas, sino que dicha competencia sea un proceso transversal en la formación de los estudiantes.

Con esta premisa, el gobierno nacional desde el 2003 se centra en que los ciudadanos sean formados, desde las instituciones educativas, en la capacidad de promover y ejercer los derechos humanos, comprometidos con la democracia, generando y promoviendo valores éticos, actitud de convivir en paz, respetar las opiniones del otro, en un ambiente donde se contribuya a la igualdad, a la equidad, y donde se incentive la participación democrática desde el espacio escolar.

De acuerdo con lo anterior, el Ministerio de Educación Nacional (MEN) define las competencias ciudadanas como "el conjunto de conocimientos y de habilidades cognitivas, emocionales y comunicativas que, articulados entre sí, hacen posible que el ciudadano actúe de manera constructiva en la sociedad democrática" (2004, p. 6). Complementado esta definición, autores como como Chaux, Lleras y Velásquez (2004) aclaran que al desarrollar estas competencias el estudiante estará en posibilidad de utilizarlas en cualquier entorno en el que pueda llegar a ser vulnerado, tanto con acciones propias como por los demás, lo anterior, con el fin de fomentar respeto, defensa y promoción de los derechos humanos fundamentales y así, saber actuar en la vida cotidiana.
Teniendo presente lo anteriormente descrito de manera superficial, queda claro que uno de los esfuerzos más notorios desde la educación para contrarrestar el fenómeno de la violencia en la sociedad es a través del favorecimiento del desarrollo de la convivencia y paz, y específicamente de las competencias ciudadanas, lo cual se viene realizando desde ya hace varias décadas (Rodríguez-Bustamante et al., 2018). Por tal razón es necesario identificar esas estrategias educativas reportadas en la literatura y agruparlas, con el propósito de construir un insumo que les permita, a profesores e instituciones, seguir trabajando en este tema y responder a esta necesidad que urge a la sociedad contemporánea. En ese esfuerzo se revisaron diferentes estrategias de diversos países de Iberoamérica, identificando los contextos, actores o ámbitos en los que se han desarrollado tales como: el entorno social, el entorno escolar, el conflicto y la resolución de conflictos, la violencia, los estudiantes, los docentes y la familia (Rodríguez, López y Echeverri, 2017).

Esas estrategias fueron agrupadas en cuatro grandes categorías, a saber: las estrategias de prevención, de participación, de intervención y las estrategias que involucran el uso de las Tecnologías de la Información y la Comunicación (TIC).

Las estrategias de prevención son aquellas que asumen el conflicto como una situación positiva que genera aprendizaje y en lugar de reunir esfuerzos por evitarlos, estas estrategias proponen desarrollar habilidades y aptitudes socioemocionales para afrontar las situaciones conflictivas de manera pacífica, a través del diálogo y la negociación, evitando la violencia escolar y transformando los conflictos en situaciones de aprendizaje significativo (Reyes y García, 2015).

Las estrategias de participación son aquellas que buscan poner en acción instrumentos, técnicas y herramientas para la participación democrática y a partir de allí generar conciencia ciudadana para la resolución democrática de los conflictos. Entre estas estrategias se encuentran: la elaboración de planes de convivencia, la creación de mesas de diálogo, la consolidación de comisiones de convivencia escolar, los proyectos de aula para la resolución de conflictos, la elaboración de manuales de 
convivencia para el abordaje, clasificación y resolución de los conflictos (Fernández, 2012).

Las estrategias de intervención son aquellas que buscan actuar de forma directa e inmediata en la resolución de una situación violenta. Se destacan entre ellas los programas de intervención en habilidades sociales para reducir el grado de acoso escolar en los colegios, y también los cursos y talleres dirigidos hacia la formación de habilidades interpersonales y sociales que permitan a los estudiantes afrontarlo (Ferreira y Muñoz, 2011).

Por último, las estrategias que involucran el uso de TIC son aquellas que buscan contribuir al fortalecimiento de la convivencia en las instituciones educativas, a través de la integración de las Tecnologías de la Información y la Comunicación, posibilitando la construcción y re-significación de la convivencia escolar, destacándose entre estas estrategias aquellas que validan las posibilidades que el uso de las tecnologías como la fotografía, los medios audiovisuales o la web y las aplicaciones móviles pueden aportar como recursos educativos y terapéuticos en la resolución de conflictos (Amaro, 2015).

\section{Aspectos metodológicos}

El presente artículo gira en torno a una revisión sistemática de literatura que permitió identificar y agrupar las estrategias que se han enfocado en favorecer la convivencia y paz en educación en algunos países de Iberoamérica. Dicha revisión se ha elaborado bajo la perspectiva de Londoño, Maldonado y Calderón (2016), quienes postulan que este proceso de investigación requiere seguir unos pasos fundamentales, delimitar el objeto de estudio y las posibles relaciones con otros temas de interés, identificar actores y referencias bibliográficas, comparar métodos de producción académica y, de esta manera, establecer comparaciones con otros conocimientos paralelos, compartir la información hallada, generar demanda de nuevo conocimiento y ofrecer nuevas posibilidades de comprensión y abordaje del problema estudiado.

En consecuencia, desde esta perspectiva la ruta metodológica del presente artículo se ha desarrollado en tres momentos que son: momento inicial, momento heurístico y momento hermenéutico.

\section{Momento inicial}

De acuerdo con Londoño, Maldonado y Calderón (2016), en esta fase es necesario tener claridad sobre el tema a investigar y específicamente definir la pregunta problema, pues a partir de ella se inician las orientaciones sobre la búsqueda, selección, organización y disposición de las fuentes de información con el propósito de planear y emprender la revisión sistemática.

Teniendo en cuenta lo anterior, este primer momento de la investigación se caracterizó por la construcción de la siguiente pregunta: ¿cuáles han sido las estrategias para desarrollar la convivencia y paz entre el 2013 y 2017 en el contexto iberoamericano?

A partir de esta pregunta se definieron las palabras claves y la respectiva ecuación de búsqueda luego de una revisión de nociones conceptuales que permitían acotar y delimitar el campo de indagación teniendo en cuenta el Tesauros de la Unesco y la Cartilla de Estándares Básicos de Competencias Ciudadanas elaborada por el Ministerio de Educación Nacional (2004). El resultado final condujo a definir la siguiente ecuación: competencias ciudadanas AND convivencia y paz AND entorno escolar. La ecuación se planteó en español, pues el propósito siempre estuvo centrado en el contexto iberoamericano.

\section{Momento heurístico}

Para Londoño et al. (2016), la heurística es el momento investigativo que implica buscar, indagar, encontrar y descubrir en documentos, fuentes históricas, o fuentes digitales, la información necesaria para realizar una revisión de procesos investigativos e identificar las formas de resolución de problemas específicos en diversos ámbitos científicos, esto con el fin de hallar los objetivos, procedimientos, metodologías y resultados que se llevarían a cabo para la resolución del problema investigativo y, a partir de allí, poder generar hallazgos, nuevos conocimientos, demostrar una aseveración o por el contrario refutarla, o también para diseñar una hipótesis epistemológica como principio rector de una investigación. 
De acuerdo con lo anterior, el momento heurístico del presente artículo se caracterizó por dar inicio al rastreo de la información partiendo de la ecuación de búsqueda definida en la fase anterior, con el filtro de búsqueda de los últimos cinco años 2013-2017. Se tuvieron en cuenta las siguientes bases de datos especializadas por su cercanía con el contexto que delimitaba la pregunta orientadora: Scielo, Redalyc, ProQuest y Google Académico. Se seleccionaron dichas bases de datos por la suficiente producción académica y científica, el alto grado de visibilidad internacional y el auge de consulta y divulgación de las publicaciones que se indexan allí.

La búsqueda inicial arrojó un total de 48 artículos eliminando duplicados, sobre los cuales se realizó un proceso de lectura inicial que permitió descartar 5 artículos que no aportaban a la pregunta de investigación. De esta manera la muestra definitiva quedó compuesta por 43 artículos distribuidos de la siguiente manera: 28 Redalyc, 11 Scielo, 2 ProQuest y 2 Google Académico.

\section{Momento hermenéutico}

Para Londoño et al. (2016), la hermenéutica es una herramienta metodológica que permite explicar, traducir e interpretar las posibles relaciones existentes en un fenómeno de estudio y el contexto en el que este acontece, a fin de comprender e interpretar la realidad de un objeto de estudio específico. Los autores manifiestan que el momento hermenéutico identifica las propuestas conceptuales y metodológicas a partir de las fuentes de información obtenidas. Es preciso mencionar que la pregunta problema se configuró como el horizonte que permite ubicar el problema desde el cual se genera el interrogante central, y le brinda sentido, explicación y comprensión a dicho interrogante.

Para esto se propuso una matriz que sistematizaba de cada artículo los siguientes datos: el año, país, resumen, palabras clave, objetivo, población, metodología, estrategia implementada, resultados, hallazgos de la investigación, y un último foco denominado aportes, que registraba las contribuciones de cada artículo a la consolidación de la respuesta a la pregunta orientadora. Como complemento de ese análisis, se construyó una unidad hermenéutica en Atlas.ti, que facilitó el análisis, codificación y segmentación a través de las categorías definidas a priori y algunas emergentes, acordes con la pregunta de investigación (ver Tabla 1).

El proceso de codificación se realizó teniendo en cuenta lo sugerido por Glaser y Strauss (1967) en la teoría fundamentada cuando hablan de codificación abierta, axial y selectiva con la finalidad de comprender el fenómeno estudiado. Para el

Tabla 1. Cuadro de categorías para análisis

\begin{tabular}{l|l}
\hline Categorías & Descriptores \\
$\begin{array}{l}\text { 1. Competencias } \\
\text { ciudadanas }\end{array}$ & $\begin{array}{l}\text { "Las competencias ciudadanas son el conjunto de conocimientos y de habilidades cognitivas, } \\
\text { emocionales y comunicativas que, articulados entre sí, hacen posible que el ciudadano actúe de } \\
\text { manera constructiva en la sociedad democrática" (MEN, 2010, p. 3). }\end{array}$ \\
\hline 2. Convivencia y paz & $\begin{array}{l}\text { "La convivencia y la paz se basan en la consideración de los demás, y especialmente, en la } \\
\text { consideración de cada persona como ser humano" (MEN, 2004). }\end{array}$ \\
\hline 2.1 Entorno Social & $\begin{array}{l}\text { De acuerdo con Pérez, J (2008), el entorno social de un sujeto se compone de varios aspectos tales } \\
\text { como su condición de vida y trabajo, su grado de escolaridad, su nivel de ingresos y la comunidad en la } \\
\text { que convive y de la que forma parte. }\end{array}$ \\
\hline $\begin{array}{l}\text { Desde la perspectiva de Torrego y Aguado (2006), la concepción del conflicto ha tenido una transición, } \\
\text { ha pasado de ser sinónimo de desgracia, a asumirse como un proceso natural y consustancial a la } \\
\text { naturaleza humana, entendido así como un fenómeno de incompatibilidad entre personas o grupos, } \\
\text { mediante el cual se perciben o afirman intereses, valores o afirmaciones contrarias. Los elementos que } \\
\text { intervienen en el conflicto son, básicamente, tres: las personas, el proceso y el problema o diferencias } \\
\text { esenciales. }\end{array}$ \\
\hline
\end{tabular}


Continuación Tabla 1. Cuadro de categorías para análisis

\begin{tabular}{|c|c|}
\hline Categorías & Descriptores \\
\hline 2.3 Violencia & $\begin{array}{l}\text { La Organización Panamericana de la Salud }\left(\mathrm{PAHO}^{*}, 2003\right) \text { define la violencia como: "el uso } \\
\text { intencional de la fuerza o el poder físico, de hecho o como amenaza, contra uno mismo, otra } \\
\text { persona o un grupo o comunidad, que cause o tenga muchas probabilidades de causar lesiones, } \\
\text { muerte, daños psicológicos, trastornos del desarrollo o privaciones" (p. 3). }\end{array}$ \\
\hline $\begin{array}{l}2.4 \text { Resolución de } \\
\text { conflictos }\end{array}$ & $\begin{array}{l}\text { De acuerdo con Pereira, (2012), la resolución y el manejo de los conflictos es un tema que se viene } \\
\text { desarrollando como una manera de apaciguar los ambientes donde se generan desacuerdos e } \\
\text { inconformidades por parte de las personas que habitan dicho entorno, previniendo o evitando } \\
\text { inconformidades y desacuerdos internos por medio de la utilización de las diferentes herramientas } \\
\text { que permiten resolver las diferencias prevaleciendo el interés general pero acentuando los casos } \\
\text { particulares que pueden llegar a ser generadores de disputa en momentos específicos. }\end{array}$ \\
\hline 3. Entorno escolar & $\begin{array}{l}\text { Se puede definir como la relación que se tiene entre todos los miembros de una comunidad escolar y } \\
\text { la manera de comunicación de cada uno. Así mismo, como el vínculo que se genera entre docentes, } \\
\text { directivos, estudiantes y administrativos, y la manera de aprendizaje que maneja cada uno de ellos. } \\
\text { "Los miembros de la comunidad educativa participan efectivamente en las decisiones importantes } \\
\text { para la escuela, construyendo relaciones armónicas y pacíficas, reconocen la riqueza de la diferencia y } \\
\text { se comprometen con la promoción de los derechos humanos" (Chaux, Lleras y Velásquez, 2012. p. 84). }\end{array}$ \\
\hline 3.1 Estudiante & $\begin{array}{l}\text { Se puede definir un estudiante como la persona que toma alguna enseñanza ya sea en un } \\
\text { establecimiento o de manera autónoma y cuya vinculación con el aprendizaje se caracteriza por la } \\
\text { búsqueda de nuevos conocimientos sobre un área de interés. }\end{array}$ \\
\hline 3.2 Docente & $\begin{array}{l}\text { Se define como un formador de ciudadanos capaz de leer los contextos tanto sociales como globales } \\
\text { en los cuales se desarrolla el estudiante. Es un facilitador que domina una disciplina, a través de } \\
\text { metodologías que ofrecen diversos lenguajes para que cada uno aprenda a vivir en armonía con los } \\
\text { demás y sean productivos en cualquiera de los contextos de la vida cotidiana. }\end{array}$ \\
\hline 3.3 Familia & $\begin{array}{l}\text { La Convención de los Derecho Humanos (1969) y afirma que la familia es "el grupo fundamental de } \\
\text { la sociedad y el medio natural para el crecimiento y bienestar de todos los miembros, especialmente } \\
\text { de los niños", por esta razón debe recibir la protección y asistencia necesaria para asumir sus } \\
\text { responsabilidades dentro de una comunidad. }\end{array}$ \\
\hline Estrate & $\begin{array}{l}\text { Se refiere a las estrategias pedagógicas que se implementaron para favorecer y/o fortalecer el } \\
\text { desarrollo de la competencia de ciudadanía y paz en educación. }\end{array}$ \\
\hline
\end{tabular}

* Por sus siglas en inglés.

Fuente: elaboración propia.

presente artículo la codificación abierta correspondió a la identificación de las categorías y subcategorías correspondientes y su conceptualización.

La codificación axial tuvo como propósito establecer relaciones entre las categorías y sus subcategorías para encontrar aproximaciones y distanciamientos entre la información analizada, identificando explicaciones precisas sobre los fenómenos estudiados. Para esta relación se elaboró la red semántica y una matriz de análisis en la que se relacionan los artículos analizados con las categorías y subcategorías, identificando los conceptos principales y cómo fueron abordados, las metodologías de implementación y principalmente las estrategias pedagógicas que buscan formar la competencia de ciudadanía y paz en educación.
Para finalizar, la codificación selectiva implica la elección de una categoría que será el núcleo o eje transversal, el cual permite establecer las relaciones entre todas las demás categorías y subcategorías. Para la presente revisión documental, "estrategias" es la categoría transversal que permite establecer relaciones entre los artículos analizados, identificar avances en torno al tema y responder a la pregunta de investigación.

A continuación, se presenta la red semántica en la cual se evidencia cada una de las categorías y subcategorías que sirvieron para el análisis y que se muestran como hallazgos y resultados. Ver Figura 1. 


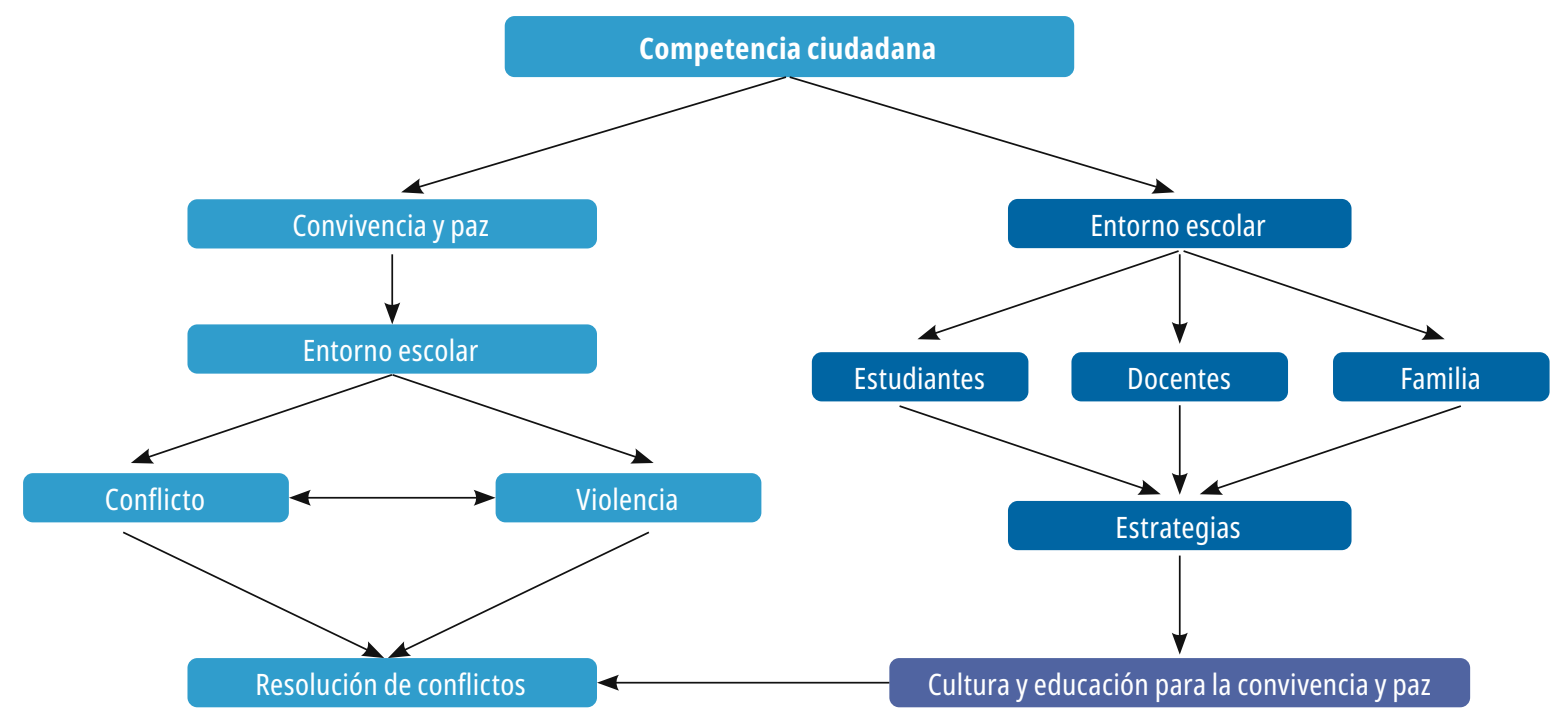

Figura 1. Red semántica de categorías y subcategorías para análisis.

Fuente: elaboración propia.

\section{Análisis}

A continuación, se presentan los resultados de análisis de los 43 artículos, en los cuales se han identificado las estrategias para la implementación o desarrollo de la competencia de convivencia y paz en educación.

De acuerdo con la matriz de análisis, entre los años 2013 y 2017 existe una mayor publicación de artículos relacionados con el tema. Ver Figura 2.

Tal como se describió en la fase hermenéutica, la ruta para el procesamiento de la información

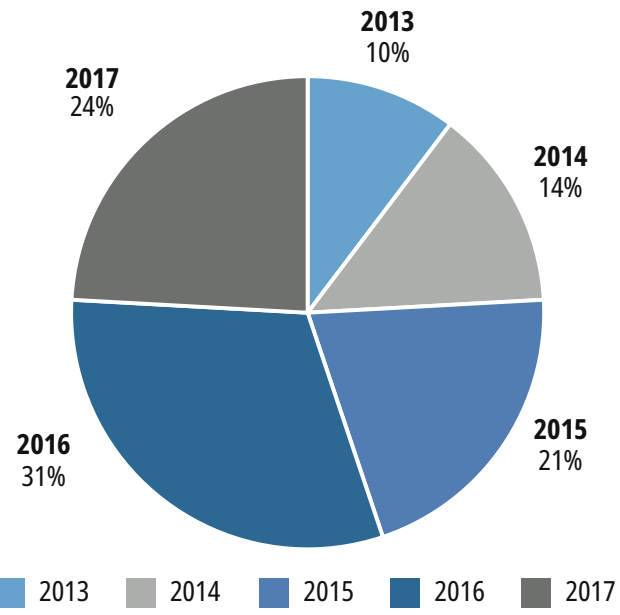

Figura 2. Relación de artículos por año de publicación. Fuente: elaboración propia. está definida por la pregunta de investigación, y teniendo en cuenta los criterios se estructura el siguiente apartado de análisis de categorías y subcategorías que se fundamentan como criterios de comprensión, a saber, competencias ciudadanas, convivencia y paz, entorno escolar.

A partir de lo anterior, se consolidan las subcategorías que permitieron establecer diálogos de comprensión y un proceso de triangulación, para generar los hallazgos investigativos y el análisis del estado del conocimiento de la pregunta problema.

\section{Competencias ciudadanas}

De acuerdo con el Ministerio de Educación Nacional (MEN, 2004), "las competencias ciudadanas son un conjunto de habilidades cognitivas, emocionales y comunicativas, que debemos desarrollar desde pequeños para saber vivir con los otros y, sobre todo, para actuar de manera constructiva en la sociedad" (p. 1).

Es preciso mencionar que esta categoría de competencias ciudadanas, si bien su conceptualización es abordada en la mayoría de las fuentes de información, no en todas es denominada con el mismo nombre. De hecho, los artículos provenientes de Colombia son los únicos que establecen las competencias ciudadanas como una política pública educativa, en otros países es denominada 
de diferentes maneras, como se describe más adelante.

Los artículos pertenecientes a Colombia toman como referente teórico al Ministerio de Educación Nacional (2010), destacando que estas competencias ciudadanas permiten que los individuos aporten a la sana convivencia, donde se destaque el respeto a las diferencias y predomine la participación en procesos democráticos que contribuyan a lograr la paz desde el ámbito educativo. La política del MEN resalta que las competencias ciudadanas se dividen en tres grupos: convivencia y paz; identidad y valoración de las diferencias; participación y responsabilidad democrática y, por último, pluralidad. Adicionalmente, se clasifican dichas competencias en cuatro tipos a saber, cognitivas, emocionales, comunicativas e integradoras.

Todos los artículos revisados exponen que las instituciones educativas son escenarios que permiten orientar el desarrollo de las competencias ciudadanas, cuando se logra en ellas generar espacios de toma de decisiones, donde se implemente la cultura democrática y el respeto a la opinión del que está al lado, además de promover, incentivar y fortalecer las estrategias pedagógicas para fortalecer la práctica de la competencia de convivencia y paz, dinamizar los espacios de participación y mediar en la prevención y resolución de los conflictos.

Una estrategia encontrada es capacitar a los docentes, con actividades como 'Wayna' (palabra que en quechua significa joven): "un material pedagógico para la convivencia que fue adaptado al contexto cultural, lingüístico, histórico y étnico de Colombia" (MEN, 2018), para que los maestros, a su vez, tengan herramientas para desarrollar con sus estudiantes tareas que les permitan promover, además de una convivencia sana, los conceptos teóricos propios de las competencias y que, al mismo tiempo, los estudiantes los transmitieran a sus familias, formando así una cadena de ciudadanos comprometidos con la sociedad, la convivencia y la paz.

Ahora bien, al definir las competencias ciudadanas como habilidades cognitivas, emocionales y comunicativas que se generan para la paz, donde se antepone la consigna de la construcción de una sociedad con valores, participación y conciencia democrática, es posible observar que son tema de interés internacional, sin embargo, en otros países el trabajo por competencias ciudadanas se desarrolla a partir de diferentes estrategias y políticas públicas.

De acuerdo con Salazar (2014), en México la ilegalidad y las malas prácticas sociales proliferan, desmejorando la imagen del país ante el mundo, por lo cual se ha buscado desarrollar competencias ciudadanas trasladando el tema a la política y a la necesidad de hacer ver el país como un sitio de cambio, de restablecimiento de derechos y capaz de encontrar, favorecer y fortalecer la paz desde la educación. Adicional a esto, la Secretaría de Educación Pública de México promueve un programa llamado Convive (Gutiérrez y Pérez, 2015), que genera espacios de participación y, teniendo como eje central los derechos humanos, defiende a la comunidad educativa con líneas telefónicas de atención inmediata, todo esto para favorecer las competencias ciudadanas.

El propósito del programa de formación ciudadana es construir una nueva posibilidad democrática, teniendo como premisa entonces que, desde la educación, se sea capaz de contribuir a formar ciudadanos capaces, responsables, competentes, comunicativos y con el conocimiento constante y continuo de su país y el medio en que se desenvuelven. De acuerdo con Gutiérrez y Pérez (2015), las competencias se analizan desde tres puntos fundamentales: las personas, los medios de comunicación y los instrumentos de información, y tienen como referente la concepción del individuo como ciudadano comprometido con la sociedad, siempre en busca del bien común.

Los artículos provenientes de Chile desarrollan este programa con el nombre de Formación Ciudadana, llamado antes Educación Cívica (Mineduc, 2015). De acuerdo con García y Méndez (2017), el programa nace de la necesidad de incentivar la paz desde el campo educativo, formando en derechos y deberes humanos, la comunicación y la participación igualitaria, además del menester de dar a conocer los diferentes mecanismos de acción y participación ciudadana.

En general, una buena parte de la literatura revisada expone que la finalidad de la educación 
cívica es que desde la escuela se fomente el interés sobre los temas sociales, ya que los mecanismos de participación son poco utilizados, la gente poco sale a votar, incluso manifiestan que no sirve de nada. Desde su formación ciudadana, un estudiante puede incentivar a su familia, y esta a sus amigos, para conocer y poner en práctica la democracia, de lo que resulta el fortalecimiento los gobiernos y las políticas que promueven estas competencias. Entonces, se debe potenciar y promover el desarrollo de la ciudadanía activa, la humanización de las relaciones sociales, contribuir en restablecer el tejido social, fomentar los derechos humanos desde el jardín infantil trabajando en ellos y poco a poco, a medida que va creciendo, resaltar todo lo relacionado con derechos humanos y así generar conciencia de ciudadano y ciudadanía. Como expone Sandoval (2014), la idea es formar estudiantes en un ambiente democrático, que la escuela sea el espacio de aprendizaje desde las acciones cotidianas y el diario vivir.

A partir de los artículos revisados, es posible identificar que la formación ciudadana en Chile se divide en tres orientaciones: "comprensión de la información y los procesos sociales; comunicación y valoración de los derechos y deberes ciudadanos y evaluación y participación en una sociedad plural" (Retuert y Castro, 2017).

De Bolivia se hallaron dos artículos que describen la formación para la educación ciudadana, donde se estudian los derechos humanos y la cultura ciudadana (Ferreira y Muñoz, 2011). El propósito de este programa es formar profesores y estudiantes comprometidos, con valores éticos y morales sobre el individuo como ciudadano. El proceso se inicia desde primaria, pero los profesores que se capacitan solo son los de secundaria, los cuales deben replicar la información.

En España, el programa se llama Educación para la Ciudadanía Democrática (Martínez y Riquelme, 2009). Se implementa con el fin de mejorar la calidad educativa, pero en él no se habla de valores, sino de principios, que los estudiantes sean capaces de consagrar sus principios y exteriorizarlos para lograr una mejor ciudadanía. Estos cambios inician desde las políticas públicas, donde se promueven políticas que fortalecen e incentivan la participación ciudadana y democrática, evidenciando la importancia de la interacción humana y la toma de decisiones.

Es preciso destacar que, en España, de acuerdo con Fernández (2008), se puede observar que se educa ciudadanos a través de la enseñanza de la historia del país, ya que se denota la preocupación respecto a que los jóvenes se interesen por los temas sociales, reconozcan y utilicen los métodos de participación, encaminados a la responsabilidad en sus acciones y cuenten con el criterio para una toma de decisiones acertadas. Como expone Duarte (2005), los estudiantes serán capaces de interpretar su realidad individual y social que permita fortalecer la sociedad en la democracia responsable. Entiéndase que no es llenar al estudiante de conocimientos y conceptos de historia, sino a través de la historia lograr construir valores que formen ciudadanos éticos.

Ante este panorama es preciso mencionar que países como Colombia, Chile, México y España llevan desde el año 2013 desarrollando estrategias y políticas públicas de competencias ciudadanas, que permitan la formación de ciudadanos íntegros; sus artículos evidencian avances y mejoras de interés en el tema, así como una amplia producción académica del mismo. En Bolivia, en cambio, aún no se evidencia un avance significativo del tema de acuerdo con las publicaciones que entraron en análisis.

También es posible observar que existe una necesidad nacional e internacional latente, de formar estudiantes y ciudadanos a partir de las competencias ciudadanas, comprometidos con la sociedad y sobre todo consigo mismos. Se observa así mismo que la base para la paz es entender que existen diferencias, conflictos en la cotidianidad de la realidad escolar, pero que, con estrategias pedagógicas es posible formar seres humanos comprometidos con la democracia, siendo conscientes que se logra la paz a través de una sana convivencia, el ejercicio de principios y valores, y la toma de decisiones.

\section{Convivencia y paz}

De acuerdo con Carmona y Hernández (2017), esta competencia y en general las competencias 
ciudadanas deben ser desarrolladas desde todas y cada una de las áreas del conocimiento, tomando como punto de partida los valores éticos y morales inculcados en casa, y desde un claro reconocimiento de las vulneraciones que podemos encontrar en algunas de las comunidades educativas. Para Cárdenas, Parra y Rico (2017), es imprescindible que estas competencias lleguen a los niños, niñas, jóvenes, familias y comunidades educativas en general, a través del disfrute de actividades dinamizadoras y estrategias pedagógicas que reconozcan la importancia de la promoción de las competencias ciudadanas en el ámbito escolar. Con esto se hace posible que, al interiorizar el significado de su importancia, también se logre exteriorizarlo en la replicación de las enseñanzas desde los mismos estudiantes hacia las personas que los rodean, lo que además puede generar mecanismos suficientes de participación que incentiven la convivencia escolar y la promoción de la paz, en diversos contextos.

Según el Ministerio de Educación Nacional de Colombia (MEN, 2014), la convivencia se define como "la capacidad de las personas para establecer relaciones sociales y humanas de calidad, fundamentadas en la tolerancia y el respeto" (p. 6). Esta calidad de las relaciones sociales no solo se define en contextos sociales, sino también culturales y normativos en los que se reconoce la individualidad.

Por su parte, Vargas (2016) menciona que la convivencia implica en sí misma establecer relaciones en las que se ven inmersos los valores adquiridos, las actitudes y las formas de ver el mundo, indicando que las interrelaciones que se generan -tanto positivas como negativas- en el ambiente escolar deben ser el centro de estudio de la convivencia.

La estrategia "pedagogía de la confianza" (Pinilla y Mendieta, 2017) entiende la convivencia como una habilidad social y comunicativa que es preciso formar en los estudiantes desde sus primeros años de vida para que logren el pleno desarrollo del potencial humano, en un entorno de convivencia pacífica que es la base de la democracia. Las investigaciones desarrolladas en torno a la competencia de convivencia y paz giran en torno al desarrollo de una cultura de paz en los contextos escolares.
Se logran identificar, en Reyes y García, estrategias que buscan la prevención de la violencia como estrategia de paz (2015), la cual desarrolla un programa en el que se resignifica el conflicto, al asumirlo de forma positiva y preparar a los estudiantes en habilidades y técnicas socioemocionales para resolverlo adecuadamente.

Para abordar la categoría de convivencia y paz, en torno al presente análisis, ha resultado importante definir el entorno social y el conflicto ya que se constituyen como conceptos fundamentales de acuerdo con las investigaciones revisadas.

\section{Entorno Social}

En el marco del entorno social, se identifica la cultura de paz como el objetivo que debe alcanzar cualquier proyecto educativo. En este contexto, Cárdenas (2017) expone la paz en relación con el concepto de justicia social y desarrollo, que deben estar ligados al cumplimiento de los derechos humanos en el marco del ejercicio de la democracia. En esta definición todos los componentes de la paz se relacionan entre sí, permitiendo que se resignifiquen los conflictos de manera positiva, integrándolos en el campo educativo como motores de transformación, dado que juegan un rol fundamental en el desarrollo de la vida integral de los estudiantes y en general de los seres humanos y la sociedad.

Por otra parte, Hernández, Luna y Cadena (2017) definen la paz como "un hecho social [ligado] al ser humano desde sus inicios... La expresión de un valor que orienta el desarrollo de la cultura de los pueblos" (p. 152). De esta manera, es posible observar que la paz es un hecho social y por lo tanto educativo, concepto que es preciso reconocer en la escuela para posibilitar una convivencia que se asuma, no como la ausencia de conflicto, sino en general como un estado de bienestar social en el que impera la igualdad, la justicia social y el ejercicio de los derechos humanos.

\section{Conflicto}

Para algunas de las investigaciones revisadas, el conflicto es un evento natural en las relaciones del ser humano, ya sea por variaciones de culturas, de 
carácter, pensamientos, ideologías, etc., pero que no necesariamente se tiene que solucionar con violencia. Para Pinilla y Mendieta (2017), el conflicto es una situación social inherente a las personas que coexisten o conviven con otros, lo que se traduce en comprender que el surgimiento de una situación conflictiva no es algo malo; lo negativo es que no se prepare a los estudiantes para aprender a resolver los conflictos de forma adecuada, pues al no saber cómo abordar un conflicto, este puede llegar a convertirse en un hecho violento.

Desde otra perspectiva complementaria, Reyes y García (2015) destacan la importancia de reconocer el conflicto en el campo educativo y, con ello, la necesidad de descubrir la perspectiva positiva del conflicto. Esto es, ver el conflicto como una forma de transformar la sociedad y las relaciones humanas para un mejor ejercicio de la democracia. Para ello, es preciso reconocer en el contexto escolar las posibilidades pedagógicas que pueden ofrecer las situaciones conflictivas y, a partir de allí, generar oportunidades para construir otro tipo de relaciones, incluso también permitir a los estudiantes prepararse para la vida fuera de la escuela, aprendiendo a hacer valer y respetar sus derechos de manera no violenta.

\section{Violencia}

De acuerdo con Ramírez y Arcila (2013), la violencia es un fenómeno que se presenta en todos los escenarios escolares, en escuelas privadas o públicas, sean grandes o pequeñas, urbanas o rurales. Esto quiere decir que se trata de un problema bastante complejo pero que para este caso se puede abordar, desde la perspectiva de Fernández (2003), como la acción presente o conducta multicausal que se manifiesta tanto en el aula como en su entorno. En la investigación de Ferreira y Muñoz (2011), se elaboró precisamente una Intervención en Habilidades Sociales a través de un programa que permitiera reducir el grado de acoso escolar en los colegios, pues los niveles de violencia eran elevados y era necesario que los estudiantes aprendieran a expresar sus sentimientos de formas creativas y sin violencia.

De la misma manera la violencia se manifiesta no solo de maneras sutiles, como se dijo anteriormente, o con el acoso escolar. De acuerdo con Duarte (2005), también existen más formas de demostración de conductas violentas, tales como el vandalismo, que hace referencia al daño relativo a las propiedades, el acoso sexual, que se refiere a comentarios o acciones de índole sexual sin el consentimiento del otro, o la violencia por medio de los avances tecnológicos llamado cyberbullying. Se han planteado diferentes soluciones a este complejo problema, a lo largo de la formación y desde los planteles educativos, como la educación para la paz y la convivencia, la cultura de paz y una sana resolución de conflictos.

La educación para la paz y la convivencia es una coeducación y es una prioridad, ya que las escuelas tienen la responsabilidad - cada vez mayor- de formar ciudadanos capaces de respetar los derechos humanos, de ejercer la democracia y de relacionarse con los demás de manera constructiva (MEN, 2014).

De acuerdo con Krmpotic y Farré (2008), respecto de los programas de intervención, los hallazgos investigativos se refieren constantemente a tres factores que posibilitan exitosamente la transformación del clima social en el aula. En este sentido, los programas de intervención deben: (a) estar dirigidos a diferentes factores simultáneamente; (b) iniciar lo más pronto posible, sin esperar que la agresión y la violencia se generalicen como trato hegemónico en el ambiente escolar, y (c) sostenerse con suficiente intensidad y duración, aproximadamente de dos años, con el fin de generar un impacto realmente significativo.

Al educar para la paz, desde los planteles educativos se debe tener en cuenta: educar en la no-violencia, en los derechos humanos, en la democracia y en la tolerancia asertiva contra la malevolencia, mejorar la convivencia en el contexto y la resolución consciente de las alteraciones personales y su influencia en los colectivos, transformando las sociedades; prevenir la violencia y lograr la resolución pacífica de conflictos mediante el autoconocimiento; basarse en cualidades humanas como la conciencia, el temple y la solidaridad. Estos valores ayudan a comprender que aún aquello que genera repulsión y desagrado posee cualidades significativas que contribuyen al bienestar y mejoramiento de la vida. 
De otra forma, como estrategias para la prevención del conflicto, docentes y estudiantes plantean el respeto, la ayuda mutua y la reflexión sobre los episodios conflictivos como las mejores estrategias para la convivencia. "El reto es resolver los conflictos de una manera constructiva, no violenta, lo cual implica entender qué es el conflicto, conocer sus componentes y desarrollar actitudes y estrategias para resolverlo" (Cascón, 2009, p. 7).

Es posible comprender la educación en y para el conflicto desde la perspectiva que la sitúa como instrumento de cambio social y, así mismo, como la posibilidad de aprender a construir relaciones humanas a través de la formación de personas y ciudadanos que conviven en un ambiente de respeto y dignidad que les permita habitar un entorno de paz. Para ello, es la educación la encargada de promover y construir una cultura de paz a partir de la formación de valores en escenarios de desarrollo sostenible (Hernández et al., 2017).

\section{Resolución de conflictos}

En algunas de las investigaciones se manifiesta que, si bien existen determinadas técnicas para la resolución de los conflictos, estas pueden ayudar a la comprensión o entendimiento del conflicto, pero en realidad para la resolución de conflictos no hay recetas, ni fórmulas milagrosas. Por el contrario, Cárdenas et al. (2017) exponen que cada conflicto tiene sus propias peculiaridades, lo que implica el estudio del contexto y del conflicto en sí mismo, para generar acciones creativas que permitan su resolución pacífica; por ejemplo, para los autores, la fotografía sirve como una herramienta de intervención para mejorar la convivencia. Se trata de un dispositivo de reproductividad técnica, pero que a su vez permitió la construcción de múltiples significaciones y la puesta en interacción y diálogo en la vida cotidiana de los participantes en torno a los temas de paz, violencia e infancia.

\section{Entorno escolar}

Actualmente, la educación es uno de los ámbitos que más interés y preocupación genera a los sectores públicos, privados y a la población en general, ya que en este contexto los conflictos no solo son conocidos por la posibilidad de conllevar agresiones físicas, sino también emocionales. Por lo tanto, se debe comprender que hay factores de riesgo tanto en la familia como en el ambiente social en el que el estudiante se desenvuelve, entre las drogas y el alcohol. En este caso, Retuert y Castro (2017) proponen que la misión más importante es investigar el ambiente, el contexto histórico y el espacio de la población, para así llegar a la razón por la cual la persona reacciona de una u otra manera en diferentes situaciones de la escolaridad.

Teniendo en cuenta que, de acuerdo con Funes (2000), los pilares de una escuela son fundamentales para el desarrollo de los conflictos de cada uno de los partícipes de la misma, en tanto esta funge como instancia socializadora, instructiva y educativa, el ámbito educativo se debe basar en transformar toda la violencia que se genera de los conflictos en educación para la paz. Esto se consigue -aunque dependiendo la población- con la promoción de prácticas solidarias que permitan fomentar la convivencia democrática y el reconocimiento de la diversidad, y así mismo garantizar la formación de personas que se autoidentifiquen e interioricen con los derechos humanos fundamentales y al mismo tiempo los respeten, promuevan y garanticen una sana convivencia.

Dentro de la categoría de "entorno escolar", se identifican las siguientes subcategorías: estudiantes, docentes y familia, que se abordarán a continuación.

\section{Estudiantes}

En el ámbito estudiantil, los conflictos no se pueden evitar y siempre van a existir. De hecho, para Cascón (2009), lo que hace un conflicto negativo es la manera de solución que cada estudiante le llegue a dar, dado que el conflicto entre estudiantes no es un momento puntual, es solo un proceso que inicia con las necesidades e intereses de diferentes estudiantes y que no recibe la respectiva solución en el momento indicado, sino al que a su vez se añaden diferentes elementos como falta de comunicación, temores, desconfianza, de manera que desemboca en intentos de solución negativa como la violencia (Guerrero y Pérez, 2016). 
Por otra parte, para Buendía, Expósito, Aguadez y Sánchez (2015), en los colegios se evidencia una relación entre observar la violencia y el hecho de que cada estudiante, cada vez actúe de manera más agresiva, esto se debe a que se convierte en un círculo vicioso, dado que la exposición a la observación de la violencia genera que los estudiantes sean cada vez más agresivos; cabe aclarar que no solo incide la observación de esta, también la calidad de vida y las actividades cotidianas que cada uno de los estudiantes realiza. Lo anterior indica que cada vez los estudiantes están más expuestos a la violencia escolar y que entender cuál es el motivo por el que cada uno está expuesto a estos problemas, no solo escolares, sino en cualquier ámbito, es fundamental para identificar cómo romper este tipo de ciclos de conflicto.

\section{Docentes}

La perspectiva que el docente tiene del estudiante -la mayoría de las veces- es que se trata de alguien agresivo e indisciplinado. Esto genera que el docente inicie una etapa de temor frente a cada uno de ellos, ya que las conductas violentas que el estudiante tiene cambian la relación docente-estudiante. Además, cada institución también empieza a perder liderazgo y fuerza como agente socializador, frente a los demás contextos a los que el estudiante se enfrenta día a día (familia, entorno social, etc.) (Sánchez, 2010).

Para Sánchez (2010), el docente debe desarrollar un papel de agente y promotor de paz. Esto lo hace mediante el estudio de diferentes ítems para solucionar conflictos y, así mismo, poder ejercer su liderazgo en cualquier ámbito escolar. Algunos de los pasos que el docente puede seguir para la resolución de conflictos con los estudiantes son: la identificación de problemas reales, la elaboración de una aproximación interdisciplinar a la hora de resolver el conflicto y la capacitación y puesta en escena de habilidades e instrumentos. Por lo tanto, el docente debe actuar como terapeuta experto en todos los elementos inmersos que acompañan un aula de clase y como gestor del diálogo, con la actitud necesaria para mejorar la convivencia y lograr en su salón de clases un ambiente sano y digno para cada uno de los estudiantes.

\section{Familia}

Merino (2006) identifica que los conflictos escolares están supremamente ligados a las familias, pues son los padres quienes acuden al llamado de los docentes y directivos de cada institución para resolver los conflictos que se presentan en la institución.

La violencia en el hogar parece empujar a los estudiantes hacia afuera de la casa. De esta manera, las pandillas y los grupos armados ilegales los atraen hacia una vida de aventura, poder y violencia (Llorente, Chaux y Salas, 2005). Por lo tanto, la violencia en las familias no solo se reproduce de generación en generación, también contribuye a la violencia por fuera del hogar tanto en el ámbito social, como en el escolar e intrapersonal, aumentando el riesgo de vinculación a grupos armados ilegales.

Teniendo en cuenta lo anterior, la familia es el primer modelo de comportamiento y tiene una gran influencia para el desarrollo cognitivo, social y escolar de cada estudiante, además de modelar las relaciones que se establecen en su entorno (Ramírez, Ríos y Guevara, 2016). Por consiguiente, en todos los contextos en los cuales el estudiante se desenvuelve, y principalmente en la familia, pilar fundamental para el desarrollo adecuado de cada persona, una de las competencias más importantes a desarrollar es la habilidad comunicativa, ya que es la primera institución de la cual el estudiante debe tener el apoyo, para poder crear un ambiente de paz y armonía (Cárdenas et al., 2017).

Como conclusión, se puede enunciar que todos los contextos que rodean el estudiante están relacionados, y que debe haber un trabajo en equipo dentro de los entornos educativos para que todos los conflictos sociales, escolares y familiares se desarrollen en perfecto equilibrio, teniendo en cuenta las competencias ciudadanas estudiadas en este análisis.

\section{Hallazgos}

Este apartado se constituye a partir del análisis y resultados de la investigación, que giran en torno a la siguiente pregunta problema: ¿cuáles han sido 
las estrategias para desarrollar la competencia de convivencia y paz en educación en Iberoamérica?

A continuación, se da respuesta a la pregunta realizada, identificando en la literatura revisada cuatro grandes categorías de estrategias, que reúnen las diferentes acciones pedagógicas que han sido aplicadas en las investigaciones referenciadas. Dichas estrategias son: de prevención, de participación, de intervención y las que se apoyan en el uso de TIC.

\section{Estrategias de prevención}

Se identificó en las investigaciones analizadas el objetivo de formar a los estudiantes para una cultura de convivencia y paz, que les permita ejercer su derecho a la ciudadanía en un ambiente escolar y social de justicia y democracia. En torno a este objetivo, se han agrupado aquellas estrategias pedagógicas que proponen consolidar espacios de paz y convivencia en las instituciones educativas, con el fin de prevenir o evitar los conflictos que desencadenan acciones violentas.

Reyes y García (2015) implementan en México la prevención como estrategia de paz. La prevención para los autores, más allá de evitar el conflicto, es la posibilidad de aceptarlo, transformarlo y hacer de él un acontecimiento positivo y creativo que genere aprendizaje a través de las situaciones que presenta la vida real, lo que implica la re-significación del conflicto y su vinculación al currículo. La prevención como estrategia incluye una serie de temas específicos sobre cultura de paz que deben ser abordados por los estudiantes y de los cuales, en general, debe tener conocimiento toda la escuela, dado que estar preparados para el conflicto requiere reconocer la necesidad de tener instrumentos de actuación en las escuelas. Para este caso, los autores plantearon talleres para desarrollar habilidades y aptitudes, elaboraron junto con la comunidad educativa manuales de convivencia y protocolos de atención para casos graves. Ampliando esta idea, Ramírez y Arcila (2013) sugieren que se generen espacios dedicados exclusivamente al diálogo entre docentes y estudiantes, en el que se puedan plantear temas como el respeto, la ayuda mutua y la reflexión, sobre situaciones conflictivas que se han presentado en las instituciones.

Una forma de prevenir la violencia es planteando propuestas para la inclusión educativa a través de la planeación de la convivencia, como lo recomienda Sánchez (2010), al proponer la educación intercultural como una estrategia para la convivencia pacífica, abriendo un espacio que permita el respeto a la diferencia y el fortalecimiento de valores como la tolerancia, para promover una cultura de paz. En este sentido, Guerrero y Pérez (2016) indican que es necesario implementar la inclusión armónica como parte de la cotidianidad entre estudiantes, docentes, directivos, padres de familia y administrativos para generar ambientes de respeto, tolerancia y solidaridad que promuevan la sana convivencia. Así mismo, la Paz Integral propuesta por Salazar (2014) reúne los planteamientos de la educación intercultural como una alternativa no violenta que permite el reconocimiento de la diferencia y la construcción de una convivencia escolar pacífica. Por otra parte, Boggino (2008) propone un modelo centrado en la aceptación de la diferencia y la construcción colectiva de normas y valores, que permitan maximizar la comprensión y la autonomía de los estudiantes, para generar procesos pedagógicos orientados a la posibilidad de compartir universos de significados que se van enriqueciendo a través de la diferencia, como un valor que se pone en práctica cotidianamente.

Pinilla y Mendieta (2017) proponen la pedagogía de la confianza, como una estrategia para generar ambientes escolares de paz. Esta propuesta implica el desarrollo de acciones pedagógicas encaminadas a la concientización de la cultura de paz, para prevenir las situaciones conflictivas en el interior de las instituciones. Para ello desarrollaron una serie de actividades pedagógicas como el Club de Gestores de Paz, el Mural del Señor Cortesía, la Urna del Compromiso, las actividades deportivas, las izadas de bandera, en las que se exponen los recitales de poemas, los dramatizados y canciones con temáticas relacionadas con el buen trato y la paz.

Para prevenir la violencia, es preciso resignificar los conceptos que se tienen acerca de la paz, 
la violencia y el conflicto. Esto se puede realizar a través de la escritura y el arte como herramientas de comunicación, utilizando el lenguaje, el cual permite crear y recrear, construir y de-construir las múltiples formas de pensar, sentir y actuar en torno a estos conceptos que dan sentido a la convivencia escolar (Duarte, 2005). En este sentido, Carmona y Hernández (2017) proponen la escritura como una experiencia de paz. Dicha estrategia persigue la transformación de la comprensión del concepto de paz a través de la producción escrita en niños de quinto grado, permitiendo que, a través de un proceso cognitivo y académico, como lo es la escritura, se generen procesos de reflexión sobre situaciones de paz y de conflicto que se vivencian en el interior de la escuela. Si bien se asume que los temas de convivencia están relacionados con la comunicación, es a partir de allí que se genera la construcción de acuerdos. Es posible considerar la acción comunicativa como una estrategia para potenciar la formación de estudiantes críticos y activos, comprometidos con la transformación de la sociedad a través de las buenas prácticas de convivencia (Arístegui et al., 2005).

Desde el arte, Náñez y Castro (2016) resaltan la importancia que presentan las artes y especialmente el área del lenguaje verbal y no verbal, como una herramienta fundamental que permite la expresión de las emociones, sentimientos y estados de ánimo de los estudiantes y que, adicionalmente, los va formando en pensamiento crítico y creativo a la par que los desarrolla humanamente. $\mathrm{Al}$ reconocer la importancia del arte y el lenguaje en la re-significación de los ambientes de paz, se reconoce la creación de nuevos sentimientos y significados de la paz y la convivencia con respecto a lo que los estudiantes sienten, piensan y viven en su cotidianidad (Catzoli, 2016).

Una de las estrategias innovadoras para prevenir la violencia escolar es la creación de diálogos intergeneracionales. Rodríguez en su estudio (2002) muestra la posibilidad de abrir un espacio en el interior del aula de clase para que los estudiantes pudieran entrar en diálogo con personas adultas, con el fin de generar puentes de resignificación que permitan la comprensión, tanto de los mundos jóvenes como de los mundos adultos. $\mathrm{Al}$ posibilitar diálogos intergeneracionales, esta estrategia le permitió a la escuela visibilizarse como un espacio de socialización de experiencias, que permite la reconstrucción y significación de los roles sociales, tanto de los adultos como de los jóvenes, generando conciencia sobre la forma en que se debe actuar, para propiciar entornos de convivencia pacífica dentro y fuera de las instituciones.

Para Osornio (2016), la cultura de paz y convivencia armónica puede fomentarse a través de los juegos cooperativos, como actividades lúdicas que propicien el trabajo en equipo, la confianza, el diálogo, y generen metas comunes entre los participantes. La ventaja que presenta esta estrategia es que el juego permite interiorizar estas acciones y hacer que los estudiantes las traslapen a todas las situaciones de su vida, fortaleciendo la convivencia escolar armónica y promoviendo una paz duradera dentro y fuera del entorno escolar.

\section{Estrategias de participación}

Es preciso mencionar el interés que presentan las investigaciones por formar estudiantes para una sana convivencia escolar, pero se destacan en esta categoría las investigaciones que muestran estrategias que, a través de la participación democrática, buscan formar estudiantes que ejerzan con responsabilidad su derecho a la ciudadanía, la responsabilidad y la justicia social, esto es, hacer tangible la democracia participativa en las instituciones educativas (Gutiérrez y Pérez, 2015).

En este marco de estrategias, Fernández (2008) propone una educación para la convivencia y la paz a través del desarrollo de actitudes cooperativas, democráticas y cívicas. Esta propuesta hace explícita la necesidad de poner en acción instrumentos democráticos que permitan la participación de los estudiantes y la resolución de los conflictos por parte de los mismos. Para ello, sugieren la elaboración de un plan de convivencia que sea incorporado al proyecto educativo institucional, la consolidación de una comisión de convivencia, la elaboración de un protocolo de procedimientos específicos de actuación e intervención de los centros educativos para atender las situaciones de maltrato, discriminación o agresión que puedan padecer los integrantes de la comunidad educativa, 
lo anterior, con el fin de garantizar su seguridad y protección, así como favorecer un entorno de aprendizaje en un ambiente de cultura de paz. En esta misma línea, Pérez (1999) propone la elaboración de un proyecto educativo de convivencia escolar que propicie un clima de participación democrática a través de asambleas de aula y el aprendizaje de normas básicas para la convivencia. Dentro de estas estrategias se reconoce también la propuesta de Artavia (2015), consistente en capacitar a los docentes en mediación y resolución alternativa de conflictos, para fortalecer una cultura de paz, y en especial para que sean los docentes quienes desarrollen estrategias de convivencia novedosas en las que primen el respeto y la tolerancia frente a las diferencias.

De acuerdo con Avendaño, Paz y Parada (2016), la construcción de ciudadanía exige la elaboración de un modelo que pueda aplicarse en la escuela, que sea contextual y responda a las necesidades de cada institución educativa. De hecho, Ascorra, López y Urbina (2016) exponen que en Chile el Ministerio de Educación ha promovido una política de participación y convivencia escolar que exige a los colegios reorganizar sus actividades curriculares y vincular en ellas espacios como los consejos escolares, los centros de estudiantes y la elaboración de reglamentos de convivencia que garantizan una participación, denominada por los actores "instrumental", dado que se limita únicamente a cumplir con lo que la ley exige.

Aprender a convivir en el ejercicio de la democracia exige adoptar un enfoque de derechos humanos que genere un clima de seguridad, respeto y confianza (Yudkin, 2014), así como también fomentar relaciones de apoyo con las familias y la comunidad e integrar en el currículo la educación emocional, la formación en valores como la tolerancia, el aprecio a la diversidad, la participación democrática y la resolución no violenta de los conflictos. Para fortalecer este currículo, es preciso llevar a cabo actividades de concienciación y afianzamiento de actitudes participativas (Caballero, 2010), a través de la creación de protocolos de control, la creación del aula de convivencia y las reuniones periódicas con los padres de familia, el desarrollo de programas integrales de prevención de violencia de género (Díaz y Seoane, 2011), encuentros pedagógicos que fomenten la afectividad y relaciones interpersonales de mayor cercanía, la incorporación de las culturas juveniles a la dinámica escolar, el patrocinio del sentido de pertenencia con la institución. Con estas iniciativas, se favorece, y garantiza la participación y convivencia democrática de los estudiantes en la institución educativa (Sandoval, 2014). La puesta en escena de estas actividades afianzará un buen clima de aula que se verá reflejado en el entorno escolar.

\section{Estrategias de intervención}

Si bien las investigaciones analizadas hacen explícito el propósito de formar a los estudiantes para una cultura de paz y una sana convivencia, existen entornos escolares en los que se presentan altos índices de violencia escolar. Para tratar de mitigarlos, se han desarrollado estrategias de inmediata intervención. Es el caso de Gómez (2017), quien muestra en su investigación que el problema de la violencia no se ubica solo entre los estudiantes, sino que muchas veces existe porque toda la comunidad educativa ha aceptado que se presente la violencia en su cotidianidad, bien a través de la agresión, el maltrato físico o emocional, el acoso escolar, o bien naturalizando las acciones violentas. En estos contextos es necesario desarrollar habilidades psico-socioeducativas, a través de una capacitación integral, contextualizada y permanente, dirigida a toda la comunidad educativa con la finalidad de brindar herramientas suficientes para atender las situaciones de violencia y mitigar los altos índices de maltrato (Martínez y Riquelme, 2009). Así mismo, son necesarias las estrategias que permitan la construcción de la resiliencia en los ambientes escolares violentos, con el fin de mitigar los factores de riesgo para saber manejar las emociones después de haber experimentado situaciones de conflicto (Méndez y Mesa, 2015). Además, se requiere un modelo dinámico, holístico, educativo y multidisciplinario que permita que se generen ambientes de comunicación y se pueda evitar la ley del silencio, que es una de las prácticas que naturalizan y prolongan la violencia en los entornos educativos (López, Carvajal, Soto y Urrea, 2013). 
El acoso escolar es una de las situaciones de violencia que más se presenta en las instituciones educativas y que tiene repercusiones físicas, psicológicas y emocionales. Para reducir los niveles de acoso escolar entre estudiantes, Ferreira y Muñoz (2011) desarrollaron un programa de intervención en habilidades sociales que posibilita la expresión de sentimientos y emociones a través del arte, y permite a los estudiantes controlar sus emociones y crear metas interpersonales o sociales para poder afrontar el acoso escolar. Una estrategia para mitigar el acoso escolar es la conformación de la red de iguales (Córdoba, Del Rey, Casas y Ortega 2016), en la que si bien se reconoce que los estudiantes generan relaciones de rivalidad, competitividad extrema, malos tratos y violencia, también es posible crear una red en la que los estudiantes pueden aprender a convivir a través de las características o gustos que tienen en común $y$, de esta manera, crear una red sólida que busque fomentar la amistad y los valores para evitar los ambientes de violencia escolar.

Como estrategia para disminuir los índices de violencia escolar en Chile, se han identificado diversas propuestas. Por un lado, García y Méndez (2017), utilizaron una técnica de intervención trabajada por Caballo e Irurtia, llamada Técnica cognitivo-conductual, la cual permite "fomentar y aumentar la eficacia interpersonal para el tratamiento de gran número de problemas psicológicos y para incidir de manera positiva en la calidad de vida" (p. 154). Este entrenamiento en habilidades sociales se realizó a través de una educación vivencial y permitió el desarrollo de actividades reflexivas que generaron el diálogo, el desarrollo de la autoestima, el manejo de las emociones, el manejo y resolución de conflictos, la creación de reglas colectivas y la vinculación de los aprendizajes con el entorno familiar. Por otro lado, Baquedano y Echeverría (2013) diseñaron e implementaron un programa de intervención que promueve y favorece un ambiente escolar libre de violencia. Para ello se elaboró, en primera instancia, un diagnóstico que permitió dar cuenta de las situaciones de conflictos y violencias más frecuentes y posteriormente el diseño de actividades pedagógicas a través del arte y la lúdica, las cuales favorecieron la toma de conciencia y que los estudiantes optaran por habitar un entorno escolar libre de violencia.

\section{Estrategias que implican el uso de TIC}

Las tecnologías de la información y la comunicación (TIC) han permeado la vida humana en múltiples entornos, entre ellos el educativo. $\mathrm{Su}$ importancia en este ámbito radica en el hecho de contribuir en el fortalecimiento de la convivencia y la cultura de paz dentro de las instituciones educativas, con herramientas que los estudiantes utilizan en su vida diaria y que, en lugar de ser ignoradas o rechazadas, pueden potenciar la formación de habilidades para una sana convivencia. De acuerdo con Vargas (2016), en el marco del proyecto Las TIC en la educación de la paz y la convivencia, los docentes han desarrollado estrategias pedagógicas que se enfocan en la resolución de conflictos, la creación de espacios tecnológicos para que los estudiantes puedan controlar la ira y manejar sus emociones, como también la creación de espacios virtuales para que los docentes escriban y sistematicen las experiencias pedagógicas positivas que implican el desarrollo de problemáticas educativas en torno a la convivencia y la cultura de paz.

Es importante resaltar que, si bien el mundo cambia constantemente y se actualiza a diario a nivel tecnológico, la escuela no puede desconocer el uso de las Tic en la vida de los estudiantes, ya que las TIC hacen parte de su vida cotidiana y de sus formas de interactuar con las personas y con el mundo (Vargas, 2016). En este sentido, se hallaron estrategias que involucran el uso de la fotografía para fomentar ambientes de paz en dos sentidos. Por un lado, ha servido como estrategia que busca desarrollar la autoestima en niños y niñas con necesidades educativas especiales, a través de la educación artística para la paz y la convivencia (Amaro, 2015). Lo destacable de esta propuesta es el hecho de que implementen el uso de las tecnologías de la imagen, fotografía y vídeo, para fortalecer habilidades y destrezas en los estudiantes y generar nuevas formas de aprendizaje e interacción dentro de la escuela. El uso de las tecnologías de la imagen les permitió a los estudiantes aceptarse 
y reconocerse con sus propias necesidades, pero también permitió a la comunidad educativa reconocer que se requieren ambientes de aprendizaje innovadores, que permitan el desarrollo de habilidades socioemocionales que favorezcan la cultura de paz en las instituciones. Por otro lado, Cárdenas et al. (2017) a través de la fotografía proponen un espacio para el arte y la estética relacional que permite la construcción de múltiples significaciones, perspectivas y miradas que cada uno de los actores tiene sobre el mundo frente a los temas de paz, violencia e infancia.

\section{Conclusiones}

Después de tener todos los insumos que permiten ampliar el horizonte de comprensión de la problemática presentada, la literatura revisada demuestra que es posible identificar dentro del contexto nacional e internacional cuatro grandes estrategias de intervención que favorecen el desarrollo de la convivencia y paz en el ámbito educativo. Dichas estrategias se han agrupado y clasificado como: estrategias de prevención, estrategias de participación, estrategias de intervención y estrategias que implican el uso de las Tic.

Las estrategias de prevención se encuentran en los estudios de Sánchez, 2010; Reyes y García, 2015; Ramírez y Arcila, 2013; Guerrero y Pérez, 2016; Salazar, 2014; Boggino, 2008; Pinilla y Mendieta, 2017; Duarte, 2005; Carmona y Hernández, 2017; Náñez y Castro, 2016; Catzoli, 2016; Rodríguez, 2002; Osornio, 2016; Arístegui et al., 2005, quienes reúnen aquellas acciones pedagógicas a partir de la escritura, la literatura y el arte en las que se hace énfasis en la prevención del conflicto, el manejo de las emociones y el fortalecimiento de valores y prácticas como el dialogo, la tolerancia y el respeto.

Las estrategias de participación están presentes en Gutiérrez y Pérez, 2015; Fernández, 2008; Pérez, 1999; Artavia, 2015; Paz y Parada, 2016; Ascorra, López y Urbina, 2016; Yudkin, 2014; Caballero, 2010; Díaz y Seoane, 2011 y Sandoval, 2014. Reúnen acciones educativas a través de la participación democrática, destacándose por sensibilizar a los estudiantes frente a su responsabilidad social del derecho a la ciudadanía y realizar proyectos pedagógicos en los que se pongan en escena acciones democráticas dentro de las instituciones educativas, como la conformación de un comité de convivencia, la vinculación de los estudiantes al proyecto educativo institucional, la creación de asambleas de aula para el aprendizaje de normas básicas de convivencia y la participación en la toma de decisiones frente a los casos de convivencia.

Las estrategias de intervención propuestas por Gómez, 2017; Martínez y Riquelme, 2009; Méndez y Mesa, 2015; López et al., 2013; Ferreira y Muñoz, 2011; Córdoba, Del Rey, Casas y Ortega, 2016; García y Méndez, 2017, y Baquedano y Echeverría, 2013, plantean la necesidad de tomar medidas y ejecutar acciones para mitigar los altos índices de violencia dentro de las instituciones educativas. Esas estrategias implican el desarrollo de talleres en habilidades psico-socioemocionales que sean contextualizados y permanentes, la creación de proyectos para la resiliencia, talleres de sensibilización frente al acoso escolar y una capacitación constante a los docentes y directivos que habiten las instituciones educativas, para que actúen como agentes mediadores y enseñen a los estudiantes otras formas de manejar la agresividad, hacerle frente al maltrato físico y rechazar la violencia como alternativa para solucionar los conflictos.

Por último las estrategias que implican el uso de las TIC, expuestas por Vargas, 2016; Amaro, 2015 y Cárdenas et al., 2017, merecen una categoría única debido a que obedecen a un eje transversal sobre el cual se realizó el proceso de investigación, y en ellas fue posible encontrar el reporte de estrategias que se potencian para dos actores educativos: por un lado, la creación de espacios tecnológicos para que los estudiantes logren el manejo de sus emociones y el control de la ira; y por otro lado, la consolidación de espacios virtuales para que los docentes logren escribir y sistematizar sus experiencias positivas en torno a la convivencia y paz en sus instituciones educativas.

La revisión de la literatura permitió identificar que, en las instituciones educativas, la mayoría de los estudiantes consideran que la mejor solución para afrontar cualquier clase de conflictos es de 
una manera impositiva y, por ello, es importante buscar alternativas de solución para poder convivir en paz y armonía. Esto se logra buscando estrategias que fortalezcan los valores sociales, que logren facilitar una cultura educadora donde se promueva la paz y la sana convivencia, además de la conciencia social de respetar las opiniones del otro, resaltando lo positivo, logrando así que se genere la enseñanza y el aprendizaje en la resolución de conflictos.

Los colegios, escuelas y universidades, además de cualquier otro lugar de enseñanza, tienen un compromiso fundamental y es eliminar, mediante la educación, las causas que generan las guerras ya que, según la Unesco, es en la mente de las personas donde se ha de construir la paz. De ahí la enorme relevancia de promover actitudes positivas para resolver los conflictos que se den en el aula (mediante la no violencia).

Los entornos escolares deben ser percibidos como escenarios de convivencia sana que propendan la paz en cada uno de los integrantes de la comunidad educativa, así como generar una motivación que haga necesaria la visualización de la cultura de paz, como promotora de la actuación consciente frente a un enfrentamiento, logrando evitar conflictos que generen violencia y disociación en los estudiantes.

Es imprescindible que las estrategias de paz y convivencia estén entrelazadas con todas y cada una de las asignaturas vistas en la etapa escolar; además, que sean desarrolladas desde la primera infancia, logrando labrar un camino lleno de posibilidades infinitas en la solución de conflictos y que sean los mismos niños, niñas, jóvenes, familias y comunidades educativas en general, los que dinamicen la práctica de los valores dentro y fuera de la escuela, y así poder reconocer la importancia de la paz y la convivencia como los principales mecanismos para el desarrollo de los mismos en el ámbito escolar, posibilitando que, al interiorizar el significado de su importancia, se logren promover hacia el exterior de las instituciones educativas.

Es importante que la familia sea involucrada en la paz y la convivencia de los entornos escolares, ya que esta es la base de la sociedad. La familia es la principal fuente de los valores y la escuela la canalizadora de ellos. Estas dos entidades deben formar un solo lazo que conlleve a una formación para la construcción de la paz y para la convivencia. Este vínculo es necesario, para que se reafirme lo aprendido emocionalmente y así, permitir a los estudiantes ser más confiados y seguros, en el mundo en el que a diario están inmersos.

Finalmente, las competencias ciudadanas nos ayudan a solucionar conflictos de una manera sana y sin violencia, y del mismo modo, a impulsar un cambio social que supla la cultura de violencia actual por una cultura de paz, a potenciar una educación adecuada a las necesidades presentes y a las perspectivas de futuro, a convertir el saber en un instrumento al servicio de la paz y cultivar en las personas la capacidad de hacer un juicio sobre el futuro de la humanidad, despertando la necesidad de comprometerse.

\section{Referencias}

Amaro, A. (2015). Desarrollando la autoestima a través de la Educación Artística para la paz y convivencia con niños y niñas de Necesidades Educativas Especiales. Revista de Estudios en Sociedad, Artes y Gestión Cultural, (8). Recuperado de https://revistaselectronicas. ujaen.es/index.php/RTC/article/view/3110

Arístegui, R., Bazán, D., Leiva, J., López, R., Muñoz, B. y Ruz, J. (2005). Hacia una Pedagogía de la Convivencia. Psykhe, 14(1), 137-150. Recuperado de https://www. redalyc.org/articulo.oa?id=96714111 DoI: https://doi. org/10.4067/S0718-22282005000100011

Artavia, A. (2015). Los retos de la educación superior: entre la formación académica y la convivencia solidaria. El derecho a una cultura de paz. Reencuentro, (70), 97-112. Recuperado de https://www.redalyc.org/ html/340/34046812007/

Ascorra, P., López, V. y Urbina, C. (2016). Participación estudiantil en escuelas chilenas con buena y mala convivencia escolar. Revista de Psicología [en línea], 25(2), 1-18. Recuperado de https://www.redalyc.org/articulo. oa? id=26449350003

Avendaño, W., Paz, L. y Parada, A. (2016). Construcción de ciudadanía: un modelo para su desarrollo en la escuela. Ágora USB [en línea], 16(2). Recuperado de http:// www.scielo.org.co/pdf/agor/v16n2/v16n2a07.pdf. DOI: https://doi.org/10.21500/16578031.2444

Baquedano, C. y Echeverría, R. (2013). Competencias psicosociales para la convivencia escolar libre de violen- 
cia: experiencia en una primaria pública de Mérida, Yucatán, México. Psicoperspectivas, 12(1), 139-160. Recuperado de https://www.redalyc.org/articulo. oa?id=171025597010. DoI: https://doi.org/10.5027/psicoperspectivas-Vol12-Issue1-fulltext-210

Boggino, N. (2008). Diversidad y convivencia escolar. Aportes para trabajar en el aula y la escuela. Revista de Estudios y Experiencias en Educación [en línea], (14), 53-64. Recuperado de https://www.redalyc.org/articulo.oa?id=243117031004

Buendía, L., Expósito, J., Aguadez, E. y Sánchez, C. (2015). Análisis de la convivencia escolar en las aulas multiculturales de Educación Secundaria. Revista de Investigación Educativa [en línea], 33(2), 303-319 Recuperado de https://doi.org/10.6018/rie.33.2.211491. DoI: https:// doi.org/10.6018/rie.33.2.211491

Caballero, M. (2010). Convivencia escolar. Un estudio sobre buenas prácticas. Obtenido de Revista de Paz y Conflictos [en línea], (3), 154-169. Recuperado de https://www.redalyc.org/articulo.oa?id=205016387011

Cárdenas, F. (2017). Educación para la paz. Novum Jus, 11(1), 103-127. Recuperado de https://editorial.ucatolica.edu.co/ojsucatolica/revistas_ucatolica/index. php/Juridica/article/view/1429/1908. DoI: https://doi. org/10.14718/NovumJus.2017.11.1.4

Cárdenas, N., Parra, A. y Rico, S. (2017). Significados y prácticas sobre la construcción de paz desde la primera infancia. Aletheia, 9(2), 188-213. Recuperado de http:/www.scielo.org.co/pdf/aleth/ v9n2/2145-0366-aleth-9-02-188.pdf. DoI: https://doi. org/10.11600/21450366.9.2aletheia.188.213

Carmona, M. y Hernández, A. (2017). La escritura, una experiencia de paz. Transformación de la comprensión de paz a través de la producción escrita en niños de quinto grado. Aletheia, 9(2), 36-55. Recuperado de http://www.scielo.org.co/pdf/aleth/ v9n2/2145-0366-aleth-9-02-36.pdf. DoI: https://doi. org/10.11600/21450366.9.2aletheia.36.55

Cascón, S. (2009). La educación para la paz como competencia docente: aportes al sistema educativo. Innov. educ., 14(64). Recuperado de http://www. scielo.org.mx/scielo.php?script=sci_arttext\&pi$\mathrm{d}=$ S1665-26732014000100010

Catzoli, L. (2016). Concepción de paz y convivencia en el contexto escolar. Ra Ximhai, 12(3), 433-444. México: https://www.redalyc.org/articulo.oa?id=46146811030. DOI: https://doi.org/10.35197/rx.12.02.2016.30.lc

Chaux, E., Lleras, J. y Velásquez, A. (2004). Competencias ciudadanas: de los estándares al aula: una propuesta de integración a las áreas académicas. Bogotá: Ministerio de Educación y Universidad de los Andes. IsBN 958695-148-0. DOI: https://doi.org/10.7440/2004.01
Chaux, E., Lleras, J. y Velásquez, A. (2012). Competencias ciudadanas: de los estándares al aula: Una propuesta de integración a las áreas académicas. Bogotá: Ministerio de Educación y Universidad de los Andes. ISBN 978-958-695-148-7.

Córdoba, F., Del Rey, R., Casas, J. y Ortega, R. (2016). Valoración del alumnado de primaria sobre convivencia escolar: el valor de la red de iguales. Psicoperspectivas, 15(2), 78-89. Recuperado de https://www.redalyc. org/articulo.oa?id=171046557008. DoI: https://doi. org/10.5027/psicoperspectivas-Vol15-Issue2-fulltext-760

Díaz, J. y Seoane, G. (2011). Convivencia y aprendizaje escolar en la adolescencia desde una perspectiva de género. Psicothema, 23(2), 252-259. Recuperado de https:// www.redalyc.org/articulo.oa?id=72717169014

Duarte, J. (2005). Comunicación en la convivencia escolar en la ciudad de Medellín. Estudios Pedagógicos, 31(1), 137-165. Recuperado de https://www.redalyc. org/articulo.oa?id=173514128008. DoI: https://doi. org/10.4067/S0718-07052005000100008

Fernández, A. (2012). Educación y participación -Un sueño posible. Madrid: Entreculturas IsBN: 978-84-695-63755: www.redage.org/sites/default/files/.../EducacionyParticipacion_UnSueñoPosible.pdf

Fernández, I. (2003). Escuela sin violencia. Resolución de conflictos. México: Alfaomega.

Fernández, R. (2008). Educación para la convivencia y para la paz: desarrollo de actitudes cooperativas, democráticas y cívicas en los centros educativos. Innovación y Experiencias Educativas, (12). Recuperado de https://archivos.csif.es/archivos/andalucia/ensenanza/ revistas/csicsif/revista/pdf/Numero_12/REGINA_ FERNANDEZ_1.pdf

Ferreira, Y. y Muñoz, P. (2011). Programa de intervención en habilidades sociales para reducir los niveles de acoso escolar. Ajayu, 9(2), 264-283. Recuperado de https:// www.redalyc.org/articulo.oa?id= 461545464004

Funes, S. (2000). Resolución de conflictos en la escuela: una herramienta para la cultura de paz y la convivencia. Contextos educativos, 3, 91-106. Recuperado de https:// www.mineducacion.gov.co/1621/articles-345822_ ANEXO_19.pdf. DoI: https://doi.org/10.18172/con.466

García, A. y Méndez, C. (2017). El entrenamiento en habilidades sociales y su impacto en la convivencia escolar dentro de un grupo de primaria. Revista de Estudios y Experiencias en Educación [en línea], 16(30), 151164. Recuperado de https://www.redalyc.org/articulo. oa?id=243150283009. DoI: https://doi.org/10.21703/ rexe. 2017301511648

Glaser, B. y Strauss, A. (1967). The discovery of grounded theory. Chicago: Aldine Press. 
Gómez, A. (2017). Violencia y gestión escolar: la opinión de directores de educación básica en Colima, México. Revista Colombiana de Educación, (73). Recuperado de http://www.scielo.org.co/pdf/rcde/n73/0120-3916rcde-73-00019.pdf

Guerrero, D. y Pérez, E. (2016). La inclusión armónica desde la educación para la paz y la planeación de la convivencia. Ra Ximhai, 12(3), 383-396. Recuperado de https://www.redalyc.org/html/461/46146811027/. DOI: https://doi.org/10.35197/rx.12.02.2016.27.dg

Gutiérrez, D. y Pérez, E. (2015). Estrategias para generar la convivencia escolar. Ra Ximhai, 11(1), 63-81. Recuperado de https://www.redalyc.org/articulo. oa?id=46139401004. DoI: https://doi.org/10.35197/ rx.11.01.2015.04.dg

Hernández, I., Luna, J. y Cadena, M. (2017). Cultura de paz: una construcción desde la educación. Rev. hist. educ. latinoam., 19(28), 149-172. Recuperado de http:// www.scielo.org.co/pdf/rhel/v19n28/v19n28a09.pdf. DOI: https://doi.org/10.19053/01227238.5596

Krmpotic, C. y Farré, M. (2008). Violencia social y escuela: un relato empírico desde barrios críticos. Katálysis [en línea], 11(2), 195-203. Recuperado de https:// www.scielo.br/pdf/rk/v11n2/05.pdf. DOI: https://doi. org/10.1590/S1414-49802008000200005

Llorente, V., Chaux, E. y Salas, M. (2005). De la casa a la guerra: nueva evidencia sobre la violencia juvenil en Colombia. Bogotá: Centro de Estudios sobre Desarrollo Económico (CEDE).

Londoño, P., Maldonado, G. y Calderón, V. (2016). Guía para construir estados del arte. Bogotá: International Corporation of Networks of Knowledge. Recuperado de Bogotá: http://iconk.org/docs/guiaea.pdf

López, C., Carvajal, C., Soto, M. y Urrea, P. (2013). Factores asociados a la convivencia escolar en adolescentes. Educación y educadores, 16(3), 383-410. Recuperado de http://www.scielo.org.co/pdf/eded/v16n3/v16n3a01. pdf. DoI: https://doi.org/10.5294/edu.2013.16.3.1

Martínez, J. y Riquelme, M. (2009). La convivencia en las aulas según el alumnado de 60 de educación primaria. International Journal of Developmental and Educational Psychology, 1(1). Recuperado de https://www. redalyc.org/pdf/3498/349832320013.pdf

Méndez, C. y Mesa, Á. (2015). Exploración etnográfica de las prácticas de convivencia: una experiencia de investigación-acción en la IED, Ciudad de Villavicencio. Aletheia, 7(1). Recuperado de http://www.scielo.org. co/pdf/aleth/v7n1/v7n1a05.pdf. DOI: https://doi.or$\mathrm{g} / 10.11600 / 21450366.7 .1$ aletheia.88.103

Merino, J. (2006). La violencia escolar. Análisis y propuestas de intervención socioeducativa. Revista Compluten- se de Educación, 17(2), 189-191. Recuperado de https:// search.proquest.com/openview/a504f33270e6359cf823973a5662e85c/1?pq-origsite $=$ gscholar $\& \mathrm{cbl}=54848$

Ministerio de Educación Nacional [MEN]. (2004). Estándares básicos de competencias en Lenguaje, Matemáticas, Ciencias y Ciudadanas. Recuperado de https://www. mineducacion.gov.co/1621/articles-340021_recurso_1.pdf

Ministerio de Educación Nacional [MEN]. (2004). Competencias ciudadanas. Habilidades para saber vivir en paz. Recuperado de https://www.mineducacion.gov. co/1621/article-87283.html

Ministerio de Educación Nacional [MEN]. (2010). Competencias ciudadanas. Recuperado de https://www.mineducacion.gov.co/1759/w3-article-235147.html

Ministerio de Educación Nacional [MEN]. (2014). Política educativa para la formación escolar en la convivencia. Recuperado de https://www.mineducacion.gov. co/1621/articles-90103_archivo_pdf.pdf

Ministerio de Educación Nacional de Chile [Mineduc]. (2004). Formación Ciudadana. Recuperado de https:// formacionciudadana.mineduc.cl/estudios-y-orientaciones/

Náñez, J. y Castro, M. (2016). Educación artística y formación ciudadana: espacio para forjar la sensibilidad en la Corporación Colegio San Bonifacio, de Ibagué, Colombia. Entramado [en línea], 12(2). Recuperado de http:// www.scielo.org.co/pdf/entra/v12n2/v12n2a12.pdf. DoI: https://doi.org/10.18041/entramado.2016v12n2. 24221

Osornio, L. (2016). Juegos cooperativos como proyecto de intervención para establecer una mejora de convivencia escolar, paz y armonía: descripción de una experiencia en una escuela Telesecundaria de Aculco. $R a$ Ximhai, 12(3), 415-431. Recuperado de https://www. redalyc.org/articulo.oa?id=46146811029. DoI: https:// doi.org/10.35197/rx.12.02.2016.29.lo

Pan American Health Organization [РAно] (2003). Informe mundial sobre la violencia y la salud. Washington, D.C.

Pérez, C. (1999). Educación para la convivencia como contenido curricular: propuesta de intervención en el aula. Estudios Pedagógicos, (25), 113-130. Recuperado de https://www.redalyc.org/articulo. oa?id=173513845007. DoI: https://doi.org/10.4067/ S0718-07051999000100007

Pérez, G. (2008). La educación como respuesta a los retos que plantea la escuela. Bordón. Revista de pedagogía, 60(4), 15-29.

Pinilla, N. y Mendieta, M. (2017). Pedagogía de la confianza: una estrategia para generar ambientes escolares de paz. Análisis, 49(91). Recuperado de https://www.redalyc.org/articulo.oa?id=515558054004. DoI: https:// doi.org/10.15332/s0120-8454.2017.0091.03 
Ramírez, C. y Arcila, W. (2013). Violencia, conflicto y agresividad en el escenario escolar. Educación y educadores, 16(3). Recuperado de http://www.scielo.org. co/pdf/eded/v16n3/v16n3a02.pdf

Ramírez, L., Ríos, L. y Guevara, A. (2016). Desafíos educativos para la convivencia escolar. Ra Ximhai, 12(6), 51-69. Recuperado de https://www.redalyc.org/articulo.oa?id=46148194003. DoI: https://doi.org/10.35197/ rx.12.01.e3.2016.02.lr

Retuert, G. y Castro, P. (2017). Teorías subjetivas de profesores acerca de su rol en la construcción de la convivencia escolar. POLIS, Revista Latinoamericana, 16(46), 321-345. Recuperado de https://www.redalyc. org/articulo.oa?id=30551302015. DoI: https://doi. org/10.4067/S0718-65682017000100321

Reyes, E. y García, S. (2015). Convivencia con conflicto y sin violencia en la escuela: la provención como estrategia de paz. Ra Ximhai, 11(1), 19-32. Recuperado de https://www.redalyc.org/pdf/461/46139401001.pdf. Dor: https://doi.org/10.35197/rx.11.01.2015.01.et

Rodríguez, A., López, G. y Echeverri, J. (2017). El aula de paz: familia y escuela en la construcción de una cultura de paz en Colombia. Perseitas, 5(1), 206-223. Dor: https://doi.org/10.21501/23461780.2243

Rodríguez-Bustamante, A., Herrera-Morales, F. y Guerrero-Santacruz, M. F. (2018). La educación y su componente ético: aprender a vivir juntos y aprender a ser. Revista Universidad Católica Luis Amigó, (2), 155-165. DOI: https://doi.org/10.21501/25907565.3050
Rodríguez, E. (2002). Mundos jóvenes, mundos adultos: lo generacional y la reconstrucción de los puentes rotos en el liceo. Una mirada desde la convivencia escolar. Última Década, (16). Recuperado de https://www.redalyc.org/articulo.oa?id=19501604

Salazar, I. (2014). Educación para la paz y la convivencia escolar en el Estado de México. Ra Ximhai, 10(2), 293312. Recuperado de https://www.redalyc.org/articulo. oa?id=46131266012. DoI: https://doi.org/10.35197/ rx.10.02.e.2014.12.is

Sánchez, A. (2010). Educación Intercultural: hacia una convivencia pacífica en la escuela. Prisma Social, (5), 1-31. Recuperado de https://search.proquest.com/openview/ ae1c706a9fc26c63777acaa3f05716ae/1?pq-origsite=gscholar\&cbl $=1426338$

Sandoval, M. (2014). Convivencia y clima escolar: claves de la gestión del conocimiento. Última década [en línea], 22(41), 153-178. Recuperado de https://scielo.conicyt. cl/pdf/udecada/v22n41/art07.pdf. DoI: https:/doi. org/10.4067/S0718-22362014000200007

Vargas, A. (2016). Espacio de investigación para la educación de la paz y la convivencia apoyado por las TIC. Opción Revista Activa, 32(8), 920-935. Recuperado de https://www.redalyc.org/articulo.oa?id=31048481052

Yudkin, A. (2014). Educar para la convivencia escolar y la paz: principios y prácticas de esperanza y acción compartida. Ra Ximhai, 10(2), 19-45. Recuperado de https://www.redalyc.org/articulo.oa?id=46131266001. DoI: https://doi.org/10.35197/rx.10.02.e.2014.01.ay 